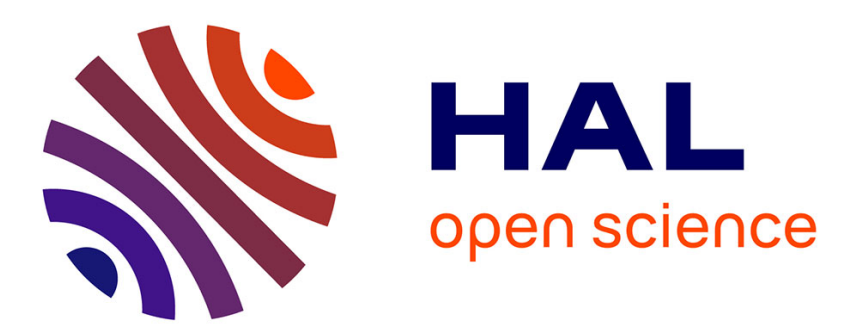

\title{
Occurrence of Dechlorane Plus and related compounds in catfish (Silurus spp.) from rivers in France
}

\author{
I. Abdel Malak, R. Cariou, A. Venisseau, G. Dervilly Pinel, F. Jaber, Marc
} Babut, B. Le Bizec

\section{> To cite this version:}

I. Abdel Malak, R. Cariou, A. Venisseau, G. Dervilly Pinel, F. Jaber, et al.. Occurrence of Dechlorane Plus and related compounds in catfish (Silurus spp.) from rivers in France. Chemosphere, 2018, 207, pp.413-420. 10.1016/j.chemosphere.2018.05.101 . hal-02068767

\section{HAL Id: hal-02068767 https://hal.science/hal-02068767}

Submitted on 15 Mar 2019

HAL is a multi-disciplinary open access archive for the deposit and dissemination of scientific research documents, whether they are published or not. The documents may come from teaching and research institutions in France or abroad, or from public or private research centers.
L'archive ouverte pluridisciplinaire HAL, est destinée au dépôt et à la diffusion de documents scientifiques de niveau recherche, publiés ou non, émanant des établissements d'enseignement et de recherche français ou étrangers, des laboratoires publics ou privés. 
1 Occurrence of Dechlorane Plus and related compounds in catfish (Silurus spp.) from rivers

3

4 Inas Abdel Malak ${ }^{1,2}$, Ronan Cariou ${ }^{1, *}$, Anaïs Vénisseau ${ }^{1}$, Gaud Dervilly-Pinel ${ }^{1}$, Farouk Jaber ${ }^{2}$, Marc $5 \quad$ Babut $^{3}$, Bruno Le Bizec ${ }^{1}$

6

$7 \quad{ }^{1}$ LABERCA, Oniris, INRA, Université Bretagne Loire, F-44307, Nantes, France.

$8{ }^{2}$ Lebanese University, Faculty of Sciences I, Laboratory of Analysis of Organic Compounds (LACO), 508 Hadath, Beirut, Lebanon.

${ }^{3}$ Irstea, RiverLy Research Unit, Lyon-Villeurbanne Center, 5 rue de la Doua CS 20244, 69625 Villeurbanne, France

*Corresponding author at: Laboratoire d'Étude des Résidus et Contaminants dans les Aliments (LABERCA), Route de Gachet, Nantes, F-44307, France

\section{Keywords}

18 Chlorinated flame retardants

19 Environmental contaminants

20 Fish muscle

21 River basin

GC-HRMS

Chemical Risk 


\section{Abstract}

Dechlorane related compounds (DRCs), including Dechlorane Plus (syn-DP and anti-DP), Dechlorane-601, -602, -603 and Chlordene Plus (CP), constitute a group of polychlorinated flame retardants (FRs) that are still of industrial use. In particular, DRCs have been detected in various environmental matrices and in different aquatic and terrestrial biota, thus exhibiting bioaccumulation and biomagnification potentials. The present study aimed at producing first occurrence data of a range of DRCs in Silurus spp. samples from different rivers located in France. Determination was carried out by gas chromatography high-resolution mass spectrometry after a sample clean-up based on a multilayer silica column and gel permeation chromatography. The concentration of monitored $\Sigma$ DRCs ranged from 1.58 to $408 \mathrm{pg} \cdot \mathrm{g}^{-1}$ wet weight (54 to $11100 \mathrm{pg} . \mathrm{g}^{-1}$ lipid weight). The fractional abundance of syn- and anti-DP stereoisomers was similar to that reported by other studies with an average equal to 0.60 . Dec-601 was not detected in any sample. Detection frequencies ranged between 34 and $100 \%$ for other DRCs. Investigated correlations between DRCs and polychlorobiphenyls (PCBs) suggest a link with lipid content but independent contamination sources. 


\section{Introduction}

Flame retardants (FRs) are chemicals added to a wide range of consumer and industrial products (e.g. textiles, furniture, wire coatings, electronics) in order to limit fire initiation and propagation in a context of fire safety (Stapleton et al., 2014). Some FRs, such as Dechlorane (also called Mirex) and decabromodiphenyl ether have been listed in Annex A of the Stockholm Convention on Persistent Organic Pollutants (POPs) (UNEP, 2001) due to their toxicity to humans and aquatic organisms (Wang et al., 2010). Thus, Dechlorane Plus (DP), a first Dechlorane Related Compound (DRC), appeared as a workable alternative (EPA, 2014). To our knowledge, DP is manufactured by two corporations in the world: OxyChem in Buffalo, NY, USA (formerly Hooker Chemical Corporation) and Anpon Electrochemical Co., Ltd in Jiangsu province in China (Xian et al., 2011).

DP is produced by a Diels-Alder condensation of two equivalents of hexachlorocyclopentadiene with one equivalent of 1,5-cyclooctadiene. Classified according to particle size, the three types of DP commercial products (DP-25, DP-35 and DP-515) are primarily composed of two stereoisomers, synand anti-isomers (Zhu et al., 2007) (see Table S1 for structures). Although some differences in the ratio of the two stereoisomers are possible due to the variability of production processes, a ratio of 1:3 (syn-DP:anti-DP) is commonly considered (Zhu et al., 2007; Jia et al., 2011). DP has been classified as a high production volume chemical in the USA but a low production volume chemical in the EU (Barón et al., 2012). Environment Canada also listed DP on Canada's Domestic Substances List (Sverko et al., 2008). The annual production was estimated to be $450-4500$ tons in the USA between 1986 and 2006 and 300-1000 tons in China between 2003 and 2005 (Wang et al., 2016). Due to its high hydrophobicity (log $K_{\text {ow }}=9.3$ ), DP presents a high tendency to adsorb onto organic materials and exhibits a long half-life in the aquatic environment (Hoh et al., 2006). It is also considered chemically stable in various environmental compartments (Wang et al., 2016). From the application perspective, DP is advantageous over brominated-based flame retardants owing to its thermal and photochemical stabilities, lower density and lower production cost (Feo et al., 2012). 
Regarding its occurrence, DP was first reported in air, fish and sediment samples from the Great Lakes region in 2006 (Hoh et al., 2006). Its ubiquitous presence has been confirmed in various environmental matrices all over the world, including wildlife and human, demonstrating that DP is persistent, susceptible to long range atmospheric transport and bioaccumulative (Sverko et al., 2011; Xian et al., 2011). Previous studies have investigated its occurrence and behaviour in the atmosphere (Hoh et al., 2006; Kakimoto et al., 2015; Xian et al., 2011), sediment (Barón et al., 2012; Xian et al., 2011; Yu et al., 2015), soil (Ma et al., 2014), water (Sverko et al., 2011), biota (L'Homme et al., 2015; Rjabova et al., 2016; Wang et al., 2015; Zhang et al., 2011) as well as food products (Aznar-Alemany et al., 2016; Kakimoto et al., 2012; Kim et al., 2014). Sverko et al. (2011) even suggested, considering DP in Annex D (candidate list) of the Stockholm Convention, so that such compounds are of public safety concerns.

At the same time, alternative DRCs based on hexachlorocyclopentadiene as well, such as Dechlorane-601, -602, -603 (Dec-601 to Dec-603) and Chlordene Plus (CP), were also placed on the market (Table S1). Little information however is available on the production volumes for these alternative DRCs (Yang et al., 2016). We did not find any information about the use or import of Dec601, Dec-602, Dec-603 and CP in France. Dec-602 may still be used in the marketplace while the environmental occurrence of Dec-603 was found to be due, in part, to its presence as an impurity in technical Aldrin and Dieldrin (Shen et al., 2011a). This family of compounds exhibits properties similar to those of persistent organic pollutants (POPs), such as long-range transport potential, bioaccumulation, biomagnification and low degradation rate (Wang et al., 2011; Von Eyken et al., 2016).

For the determination of DRCs, the majority of studies relies on gas chromatographic separation, followed either by electron ionisation or negative chemical ionisation through electronic capture mechanism, coupled to single or tandem mass spectrometry (EI-MS(/MS) or NCl-MS(/MS)) determination. These methods face insufficient detection limits in some cases with, in other cases, the need of an additional injection for separating DRCs from polybrominated diphenyl ethers (PBDEs) 
(Sales et al., 2017). Other authors implemented electron ionisation coupled to high resolution mass spectrometry for DP identification and quantification (Wang et al., 2016) to take advantage of the mass defect induced by chlorine atoms.

Fish have widely been used to monitor pollution in aquatic ecosystems. In addition, fish constitutes a critical link connecting the aquatic food web to the human. Further, consumption of contaminated fish is recognised as a major source of exposure to environmental pollutants for the general population (Bodin et al., 2014). In river fish samples from industrial areas in Korea, Kang et al. (2010) observed relatively high DP concentrations, ranging from 0.61 to $126 \mathrm{ng} \cdot \mathrm{g}^{1}$ of lipid weight (Iw) with a mean value of $24.5 \mathrm{ng} \cdot \mathrm{g}^{-1} \mathrm{Iw}$. Sun et al. (2016) reported that the DP concentrations in the Pearl River Delta (South China) ranged from 0.09 to $27 \mathrm{ng} \cdot \mathrm{g}^{-1} \mathrm{Iw}$. Another study reported DRC levels in various fish species collected in Spanish rivers: Dec-602, Dec-603 and DP were detected in almost all samples at concentrations up to $174,11.8$ and $4.9 \mathrm{ng} \cdot \mathrm{g}^{-1} \mathrm{Iw}$, with median values of $38.2,2.6$ and $0.9 \mathrm{ng} \cdot \mathrm{g}^{-1} \mathrm{Iw}$, respectively (Santín et al., 2013). Giulivo et al. (2017) investigated the presence of DRCs in three European river basins flowing into the Mediterranean Sea in fish samples collected over 2014-2015. DRCs were detected in fishes from both the Adige (Italy) and the Sava (South-East Europe) river basins, with mean values equal to 7.59 and $3.00 \mathrm{ng} \cdot \mathrm{g}^{-1} \mathrm{lw}$, respectively; they were not detected in fishes from the Evrotas (Greece) river basin. Recent studies reported mean concentrations of DRCs in fishes from two rivers from Latvia with concentrations of $14.8,0.98$ and 11.34 pg.g ${ }^{-1}$ Iw for Dec-602, Dec-603 and DP, respectively (Rjabova et al., 2016). Part of these results suggests that the prevalence of DRCs in fishes arising from production and industrial zones is higher than in rural places. To the best of our knowledge, the status of DRCs in river fish from France is yet unknown.

The aim of the present study was to report occurrence levels of DRCs in Silurus spp. from several river basins in France. This species is largely distributed over the French territory, and known to accumulate hydrophobic chemicals such as polychlorobiphenyls (AFSSA, 2008; Alomar et al., 2016; Squadrone et al., 2016). To the best of our knowledge, this is the first time that this set of emerging halogenated flame retardants was determined in fish samples in France. 


\section{Materials and methods}

\subsection{Sample collection}

A total of 102 Silurus spp. samples were collected from 22 areas covering the metropolitan French territory (Figure 1) during 2008-2011 and 2014-2015. Muscles were freeze-dried, homogenized using a stainless steel blender and stored until chemical analysis was performed.

125 100 bar and $120^{\circ} \mathrm{C}(3$ cycles) with approximately $120 \mathrm{~mL}$ of a mixture of toluene/acetone $7: 3(\mathrm{v} / \mathrm{v})$. 144 The extract was fortified with a mixture of ${ }^{13} \mathrm{C}_{10}$-labelled syn-DP, anti-DP and Dec-602 (4 ng each).

\subsection{Chemicals}

Reference solutions of native syn-Dechlorane Plus (DP), anti-DP, Dec-601, -602, -603 and Chlordene Plus (CP) were purchased from Wellington Laboratories (Guelph, Ontario, Canada). Reference solutions of ${ }^{13} \mathrm{C}_{10}$-labelled syn-DP, anti-DP, Dec-602 (internal standards, IS) and ${ }^{13} \mathrm{C}_{12}$-PCB-194 (recovery standard) were provided by Cambridge Isotope Laboratories (Andover, MA, USA) and used according to the isotopic dilution analysis. Working solutions were prepared at $1 \mathrm{ng} . \mu \mathrm{L}^{-1}$ in toluene and stored at $-20^{\circ} \mathrm{C}$. Silica gel (70/230 mesh) was obtained from Fluka (Buchs, Switzerland), sodium sulphate from Merck (Darmstadt, Germany). Sulphuric acid (98\%) was purchased from Panreac (Barcelona, Spain) and $1 \mathrm{~N}$ sodium hydroxide from Reagecon (Clare, Ireland). Toluene, acetone, ethyl acetate, cyclohexane and $n$-hexane were provided by LGC Promochem (Picograde ${ }^{\circledR}$, Wesel, Germany) and dichloromethane by Biosolve (Valkenswaard, The Netherlands).

\subsection{Sample preparation}

The procedure for sample extraction was adapted from those present in the literature (Wang et al., 2016) with minor modifications (Figure 2). Four grams of lyophilised fish muscle were extracted by Pressurized Liquid Extraction (PLE) with diatomaceous earth (Büchi, SpeedExtractor, E-914) at 
145 Extracted lipids were determined gravimetrically and reconstituted in $n$-hexane. Then, a two-step

146 clean-up procedure was applied. First, the extract was loaded on a multilayer silica gel column

147 comprising $5 \mathrm{~g}$ neutral silica gel, $5 \mathrm{~g}$ basic silica gel ( $\mathrm{NaOH} 1 \mathrm{~N}$ ), $5 \mathrm{~g}$ neutral silica gel, $20 \mathrm{~g}$ and $25 \mathrm{~g}$

148 acidic silica gel ( $22 \%$ and $44 \% \mathrm{H}_{2} \mathrm{SO}_{4}$, respectively) from the bottom to the top, and topped with dry

$149 \mathrm{Na}_{2} \mathrm{SO}_{4}$. DRCs were eluted with $120 \mathrm{~mL} n$-hexane and reconstituted in $500 \mu \mathrm{L}$ of a mixture of ethyl

150 acetate/cyclohexane 1:1 $(v / v)$. Second, the extract was subjected to a Gel Permeation

151 Chromatography column $(58 \mathrm{~cm} \times 24.4 \mathrm{~mm}$ ) packed with Bio-Beads SX-3 (Bio-Rad, Philadelphia, PA)

152 using a mixture of ethyl acetate/cyclohexane 1:1 $(\mathrm{v} / \mathrm{v})$ as mobile phase at a flow rate of $5 \mathrm{~mL}$. $\mathrm{min}^{-1}$, to

remove remaining interferences. The collected extract $(24-36 \mathrm{~min})$ was concentrated to dryness

under a gentle stream of nitrogen and reconstituted in $20 \mu \mathrm{L}$ of toluene containing $800 \mathrm{pg}$ of

${ }^{13} \mathrm{C}_{12}-\mathrm{PCB}-194$, prior to the instrumental analysis.

\subsection{Instrumental acquisition}

Purified extracts were analysed by gas chromatography coupled to high resolution mass spectrometry with electron ionisation (GC-El-HRMS). GC separation was performed in a HP 6890 instrument (HP, Palo Alto, CA, USA). Four capillary columns were evaluated: ZB-5HT Inferno (5\% phenyl, 95\% dimethylpolysiloxane; $15 \mathrm{~m} \times 0.25 \mathrm{~mm}, 0.1 \mu \mathrm{m}$ ), Rtx ${ }^{\circledR}-1614$ (5\% diphenyl, 95\% dimethylpolysiloxane; $15 \mathrm{~m} \times 0.25 \mathrm{~mm}, 0.1 \mu \mathrm{m}$ ), DB-5MS (5\% phenyl, 95\% dimethyl arylene polysiloxane; $30 \mathrm{~m} \times 0.25 \mathrm{~mm}, 0.1 \mu \mathrm{m}$ ) and HT8-PCB (8\% phenyl polycarborane-siloxane; $30 \mathrm{~m} \times$ USA), Agilent (Santa Clara, CA, USA) and SGE Analytical Science (Ringwood, Australia), respectively. The optimised chromatographic separation of DRCs was obtained using the HT8-PCB column with the conditions hereafter described. Two microliters of the extracts were injected in the splitless mode at $280^{\circ} \mathrm{C}$. Helium was used as carrier gas at $1 \mathrm{~mL} \cdot \mathrm{min}^{-1}$. The oven temperature program started at $100{ }^{\circ} \mathrm{C}(2 \mathrm{~min})$, rose to $280^{\circ} \mathrm{C}$ at $33^{\circ} \mathrm{C} \cdot \mathrm{min}^{-1}$, then ramped to $325^{\circ} \mathrm{C}$ at $5^{\circ} \mathrm{C} \cdot \mathrm{min}^{-1}(6 \mathrm{~min})$. Auxiliary and source temperatures were set at $280{ }^{\circ} \mathrm{C}$. The electron energy was set at $38 \mathrm{eV}$ and the filament 
current at $400 \mu \mathrm{A}$. HRMS measurements were achieved on a JMS 700D electromagnetic instrument (Jeol, Tokyo, Japan), operating at a resolution of 10,000 according to $10 \%$ valley definition. The target analytes were detected in the Selected lon Monitoring acquisition mode using the two most intense fragments from each molecular ion cluster (Table S2).

\section{5. $Q A / Q C$}

The analytes were identified according to the Commission Decision 2002/657/EC requirements. Particular attention was paid to procedural contamination at any stage of the analytical process. Glassware was rinsed with dichloromethane or, whenever possible, was heated in a muffle oven at $400{ }^{\circ} \mathrm{C}$ during $4 \mathrm{~h}$. PLE extraction cells with diatomaceous earth were pre-washed prior to use. Procedural blanks were performed from PLE extraction in each batch of samples and treated in the same manner as routine samples $(n=10)$. The distribution of concentration levels was then used to set a limit of reporting (LOR) by considering the mean value plus three times the standard deviation. When no procedural contamination was observed, a limit of detection (LOD) was defined as three times the noise background.

As regards to the evaluation of the method accuracy, we participated in the Northern Contaminants Program/Arctic Monitoring and Assessment Programme Phase 11 Interlaboratory Study (NCP) organised by the Ontario Ministry of the Environment and Climate Change. However, since no samples obtained $\geq 10$ numerical reported results for DRCs, no $z$-scores could be attributed for fish samples and extracts. Nevertheless, design values were available for the standard solution, with 3 to 8 reporting laboratories. Moreover, in order to monitor precision and trueness along the analytical campaign, (i) an in-house quality control (QC) fish oil (1 g aliquots) routinely used for ISO 17025 methods dedicated to a range of POPs (PCDD/Fs, PCBs, PDBEs, HBCDDs) (Jondreville et al., 2017) was either used as a non-fortified QC ( $n=5)$ or a fortified QC (QCF) (4 ng of each native compound) $(n=5)$ and (ii) a significantly naturally contaminated fish muscle sample (NCF) was analysed 4 times. 


\subsection{Data processing}

All the results were expressed both on a wet weight ( $w w)$ and on a lipid weight (Iw) basis, in order to facilitate the comparison to the results reported in other studies. The average values were expressed according to lower-bound (LB) and upper-bound (UB) approaches. The LB average underestimates the value by considering zero if the level measured in the sample is below the limits of performance (LOR or LOD). The UB average overestimates the value by considering the limits of performance (LOR or LOD) if the level measured in the sample is below.

The relationships between DRCs and PCBs (previously analysed using proven methods, not published) were statistically evaluated by Spearman coefficients of correlation ( $\rho$ ) using XLStat 2017 (Addinsoft, Paris, France).

\section{Results and discussion}

\subsection{Method performances}

With regard to achieving optimal GC separation and considering that the same ion at $m / z 271.8096$ is monitored for most target analytes, the efficiency of four capillary columns was tested: ZB-5HT Inferno, Rtx ${ }^{\circledR}-1614$, DB-5MS and HT8-PCB. While the three first ones exhibited coelution of Dec-601 and syn-DP, generating an identification issue, the HT8-PCB was the only column allowing for their separation (Figure S1). Then, the HT8-PCB column was selected for DRCs analysis.

The performance of the method was evaluated with regard to the relative response factor (linearity), the recovery, the limit of reporting (LOR) or detection (LOD) and the precision. Instrumental linearity was evaluated using five calibration standards covering the concentration range from 5 to $500 \mathrm{pg} \cdot \mathrm{\mu L}^{-1}$ for each compound, and containing the 3 labelled internal standards at $200 \mathrm{pg} . \mu \mathrm{L}^{-1}$ and the recovery standard at $40 \mathrm{pg} \cdot \mathrm{LL}^{-1}$. The obtained relative standard deviation (RSD) and the average relative factor (RRF) for each analyte is presented in the supporting information (Table S3). The values of RSD for all compounds were lower than $20 \%$, which reflects an acceptable linearity. The average recoveries for

\footnotetext{
${ }^{13} \mathrm{C}_{10}$-labeled standards were $113 \pm 17 \%, 101 \pm 14 \%$ and $74 \pm 11 \%$ for ${ }^{13} \mathrm{C}_{10}$-syn-DP, ${ }^{13} \mathrm{C}_{10}$-anti-DP and
} 
${ }^{13} \mathrm{C}_{10}$-Dec-602, respectively. Trace amounts of syn-DP and anti-DP were detected in procedural blanks with a mean concentration of approximately $1 \mathrm{pg} \cdot \mathrm{g}^{-1} \mathrm{ww}$, based on the average sample size (Table S4). Based on the approach described in section 2.5, the LOR value was equal to $3 \mathrm{pg} \cdot \mathrm{g}^{-1} \mathrm{ww}$ for both. The calculated detection limits (LOD, $S / N=3$ ) of Dec-601, $-602,-603$, and CP were 0.5, 0.1, 0.2 and 0.1 pg. $\mathrm{g}^{-1} \mathrm{ww}$, respectively. The results obtained for the NCP standard mixture showed a satisfying correlation for all the target compounds within the designed value (Table S5), which validates that the standards were properly prepared. The intermediate precision of the assay was assessed by analysing a fish sample (NCF), a non-fortified (QC) and a fortified fish oil (QCF) samples, according to the ISO 11352:2012 standards and Eppe et al. (2017) guideline. Obtained values were 14.4, 19.8, 17.9, 6.9, 21.5 and 18.9\% for syn-DP, anti-DP, Dec-601, Dec-602, Dec-603 and CP, respectively (Table S6). The trueness uncertainty was estimated based on the difference between the fortified and non-fortified fish oil, and ranged between -3.0 to $+3.0 \%$, except for CP at $+20.3 \%$ (Table S6). Finally, these accuracy results led to a relatively high confidence level regarding determination of DP isomers, Dec-602 and -603. CP suffered a slight trueness bias while Dec-601 was not completely evaluated due to non-detectable levels.

\subsection{Sum concentration of DP isomers}

Table 1 summarises the results obtained for the 102 fish samples. Despite lower detection performances compared to other DRCs, at least one DP isomer could be quantified in about half of the fish samples collected in French rivers during 2008-2015. More precisely, syn-DP was detected in $33 \%$ of the analysed samples, whereas anti-DP was found in $47 \%$.

In our study, the concentrations levels of DP in fish $(n=102)$ ranged from $\leq$ LOR to $73.8 \mathrm{pg} \cdot \mathrm{g}^{-1} \mathrm{WW}$ with an average value comprised between 8.05 (LB) and 11.63 (UB) pg.g $\mathrm{g}^{-1}$ ww. The highest concentration of DP was detected in a Silurus spp. from the Jonage channel (a branch of the Rhone River, upstream from Lyon, Figure 1), close to a hydroelectric plant. Another fish sample, from the Garonne River, also exhibited a relatively high DP level at $45.1 \mathrm{pg} \cdot \mathrm{g}^{-1} \mathrm{ww}$. This relatively high level 
was observed in the fish presenting the highest lipid content (12.2\%), which is not surprising considering the lipophilic properties of these compounds. Quite similarly, concentrations of DP reported in a recent study on salmon $(n=25)$ from Latvian rivers in 2012 reached a mean concentration of $11.34 \mathrm{pg} . \mathrm{g}^{-1} \mathrm{ww}$, taking into account values above LOR only (>50\% detection frequencies for syn- and anti-DP) (Rjabova et al., 2016). This value was about two times lower than the one found in our study based on the same calculation method ( $\left.22.9 \mathrm{pg} \cdot \mathrm{g}^{-1} \mathrm{ww}\right)$.

In order to compare our results with those of other studies, the concentration of DP was also expressed on a lipid weight (Iw) basis, ranging from $\leq$ LOR to $6.01 \mathrm{ng} \cdot \mathrm{g}^{-1} \mathrm{Iw}$ with an average value comprised between 0.56 (LB) and 1.14 (UB) ng. $\mathrm{g}^{-1} \mathrm{Iw}$. These results were an order of magnitude lower than those observed in previous studies focusing on river fish in Asia. For instance, Kang et al. (2010), reported DP concentrations from urban-industrial rivers in South Korea $(n=22)$ in 2008 at an average of 24.5 ng. $\mathrm{g}^{-1} \mathrm{Iw}$. Wang et al., reported DP in North-Eastern China $(n=15)$ in 2010 with an average equal to $29 \mathrm{ng} \cdot \mathrm{g}^{-1}$ Iw (Wang et al., 2012). However, our results were close to those reported for Spanish river basins, which ranged from non-detected to $2.24 \mathrm{ng} \cdot \mathrm{g}^{-1} \mathrm{Iw}$ (Barón et al., 2012) or from non-detected to $4.86 \mathrm{ng} \cdot \mathrm{g}^{-1}$ Iw (Santín et al., 2013). These previously reported results suggest that specific industrialized and populated urban areas could be major sources of chlorinated flame retardants.

\subsection{Profiles of DP isomers}

The concentrations of anti-DP were higher than those of syn-DP in about $85 \%$ of the quantified samples, results exhibiting a pronounced domination of anti-DP. These observations are similar to those reported by other authors (Barón et al., 2012; De La Torre et al., 2012).

The isomer ratio of DP is commonly used to assess the fate and distribution of DP in the environment and biota. The fractional abundance of the anti-isomer $\left(f_{\text {anti }}\right)$ is calculated by dividing the concentration of anti-DP by the sum concentration of syn- and anti-DP. The $f_{\text {anti }}$ value of DP commercial products varies from 0.65 to 0.80 , depending on the study. The $f_{\text {anti }}$ value in this study 
ranged from 0.32 to 0.88 with an average equal to $0.60 \pm 0.12$ (Figure 3), which is similar to previously reported values for river fishes of 0.67 (Kang et al., 2010), $0.48 \pm 0.16$ (Santín et al., 2013), 0.71 (Rjabova et al., 2016) and 0.56 (Giulivo et al., 2017). According to the literature, there is a tendency towards an enrichment in syn-DP in higher trophic levels in aquatic biota (Kakimoto et al., 2012; Xian et al., 2011). However, how can one explain the three $f_{\text {anti }}$ values observed above 0.75 ? A hypothesis could be that some exposure sources were highly dominated by anti-DP, corroborated by the fact that the concerned collection sites were close to one another (Loir and Loire rivers). Another hypothesis could be that inter-individual variability leads to specific enrichment in anti-DP in some cases.

\subsection{Concentration of other DRCS}

Dec-601 was not detected in any of the 102 fish samples analysed, possibly because not bioaccumulative or more likely because not used in the considered geographical area. Conversely, Dec-602, -603 and CP were detected in almost all the samples with a detection frequency (DF) of $100 \%, 95 \%$ and $89 \%$, respectively.

Dec-602 was the most frequently detected DRC, with levels ranging from 0.31 to $226 \mathrm{pg} \cdot \mathrm{g}^{-1} \mathrm{ww}$ (up to $\left.5.30 \mathrm{ng} \cdot \mathrm{g}^{-1} \mathrm{Iw}\right)$ and an average at $11.8 \mathrm{pg} \cdot \mathrm{g}^{-1} \mathrm{ww}\left(0.56 \mathrm{ng} \cdot \mathrm{g}^{-1} \mathrm{lw}\right)$. The concentrations of Dec-602 were higher than those of DP. Baron et al. (2012) suggested that the differences in log Kow values for Dec-602 and DP (7.1 and 9.0, respectively) could explain such a trend. The concentrations of Dec-602 were similar to those found in salmon samples $(n=25)$ collected from rivers in Latvia $(100 \% \mathrm{DF}$, average at $14.8 \mathrm{pg} \cdot \mathrm{g}^{-1} \mathrm{ww}$ ) (Rjabova et al., 2016) but lower than those reported in fish samples $(n=15)$ from a river in North-Eastern China in 2010 (100\% DF, average at $\left.7.8 \mathrm{ng} . \mathrm{g}^{-1} \mathrm{Iw}\right)$ (Wang et al., 2012).

The concentration levels of Dec-603 ranged from $\leq$ LOD to $250 \mathrm{pg} \cdot \mathrm{g}^{-1} \mathrm{ww}$ (up to $3.84 \mathrm{ng} \cdot \mathrm{g}^{-1} \mathrm{Iw}$ ) with an average at $12.5 \mathrm{pg} \cdot \mathrm{g}^{-1} \mathrm{ww}\left(0.56 \mathrm{ng} \cdot \mathrm{g}^{-1} \mathrm{Iw}\right)$. These values were much higher than those reported 
300 from Latvia at $0.98 \mathrm{pg} . \mathrm{g}^{-1} \mathrm{ww}$ (Rjabova et al., 2016) but lower than those found in China at

$3013.80 \mathrm{ng} \cdot \mathrm{g}^{-1} \mathrm{Iw}$ and in Spain at $2.46 \mathrm{ng} \cdot \mathrm{g}^{-1}$ Iw (Wang et al., 2012; Santín et al., 2013).

302 Concentration levels for CP ranged from $\leq$ LOD to $45.1 \mathrm{pg} \cdot \mathrm{g}^{-1} \mathrm{ww}$ (up to $0.94 \mathrm{ng} \cdot \mathrm{g}^{-1} \mathrm{Iw}$ ) with an average at $2.51 \mathrm{pg} \mathrm{g}^{-1} \mathrm{ww}\left(0.11 \mathrm{ng} \cdot \mathrm{g}^{-1} \mathrm{lw}\right)$. These concentrations were lower than those found in seven aquatic species $(n=66)$ in China in $2010\left(100 \%\right.$ DF, from 29.8 to $128 \mathrm{ng} \cdot \mathrm{g}^{-1} \mathrm{Iw}$,) (Wang et al., 2015). Quite similarly, De la Torre et al. (2012) reported relatively low mean CP concentrations such as sediment (Shen et al., 2011a, 2011b) and human serum (Brasseur et al., 2014; Kim et al., 2016).

\subsection{Correlations between DRCs}

Keeping in mind that concentration levels were relatively low for such a comparison, the correlation between DRCs was assessed based on wet weight concentrations, while accounting only for quantified ( $\geq$ LOR) values. The results (Table 2 ) indicate that syn- and anti-DP were moderately correlated with each other $(\rho=0.75)$, presumably because syn-DP and anti-DP (structural isomers) have different bioaccumulation properties. Several studies have shown on diastereoisomers, enantiomers or atropisomers, that the spatial conformation of the compounds can affect the properties of bioaccumulation (Wong et al., 2002; Dang et al., 2010; Luo et al., 2013). Other significant correlations were observed between syn-DP and Dec-602 $(\rho=0.38, P$-value $=0.026)$ and between Dec-603 and CP $(\rho=0.78, P<0.0001)$.

The sum of wet weight based concentrations of all DRCs ( $\Sigma D R C s)$ was correlated with lipid contents (Speaman test; $\rho=0.69, P<0.0001$ ). Dec-602, which is the dominant compound in $\Sigma$ DRCs, was also correlated with lipid contents $(\rho=0.69, P<0.0001)$. Nevertheless, beside lipids, $\rho$ value suggests that 
There was no correlation between DP and other DRCs based on lipid adjusted concentrations, nor between other DRCs themselves, except a moderate correlation between Dec-603 and CP $(\rho=0.75$; Table 2). This observation suggests that these DRCs originate from independent uses, therefore spatial sources.

\subsection{Correlation between DRCs and other POPs}

Polychlorobiphenyl (PCB) concentrations were available for 97 out of 102 Silurus spp. samples. These PCB data were obtained in the context on a national plan aiming to establish a diagnosis of freshwater fish contamination (Eaufrance). Analytes included 12 dioxin-like PCB (DL-PCB) congeners, and six non-dioxin-like/indicator congeners. It was thus possible to seek potential relationships among PCBs and dechloranes at a national scale. As DL-PCB concentrations were almost certainly correlated to the sum of $\mathrm{PCB}$ concentrations $(\Sigma P C B)$ or to the sum of concentrations of a few indicator congeners (AFSSA, 2009; Babut et al., 2009), we explored the correlation between dechloranes and six indicator congeners (PCB-28, $-52,-138,-153$ and -180 ) individually or as a single variable $\left(\Sigma_{6} \mathrm{PCB}\right)$.

$\Sigma$ DRCs and $\Sigma_{6}$ PCB appeared correlated on a ww basis $(\rho=0.67, P<0.0001, n=77)$. Among DRCs, Dec-602, which is the dominant compound in $\Sigma$ DRCs, was slightly more correlated to $\Sigma_{6} \mathrm{PCB}$ ( $\rho=0.81$, $P<0.0001)$; it was also correlated to each congener accounted for in $\Sigma_{6} \mathrm{PCB}$ (Table S7). The correlation coefficients were lower but still significant when testing correlations on a Iw basis ( $\rho=0.73$ for Dec-602 vs $\Sigma_{6}$ PCB, or $\rho=0.74$ for Dec-602 vs PCB-153). This suggests that although lipid contents are influencing the accumulation of both PCBs and DRCs, other influencing factors unexplored yet are also common to both contaminant groups. Urbanization, because emissions can result from past and present uses at industrial sites or in households, cars and so on, might be one of these.

\section{Conclusions and perspectives}


351 A robust and sensitive method has been developed and evaluated for the analysis of DRCs in fish

352 muscle. The method showed satisfying performances as preliminarily assessed, although a full validation is still required. The protocol was successfully applied to a relatively large set of fish samples from French rivers. The median concentration of $\Sigma D R C$ in Silurus spp. was observed quite low (in the pg. $\mathrm{g}^{-1} \mathrm{ww}$ range) compared to reported results from Asia where maximum values reach a few dozen or hundred pg. g $^{-1}$ ww. A moderate correlation was found between DRCs and PCBs levels, will evolve, particularly in rivers. The potential impact of such contamination from an ecotoxicological point of view, as well as consequences in terms of public health are still an open question. Moreover, it would be important to evaluate the dietary exposure of the French population, considering animal products as well as sea fish or shellfish, which could also be contaminated.

\section{Acknowledgements}

The authors express their acknowledgments to the French General Directorate for Food as well as the Lebanese Association for Scientific Research, both for the financial support. 


\section{References}

AFSSA (2008). Appui scientifique et technique de l'Agence Française de Sécurité Sanitaire des aliments relative au plan d'échantillonnage national des PCB dans les poissons de rivière : proposition de méthodologie. Report No. Saisine $n^{\circ}$ 2008-SA-0019, Agence Française de Sécurité Sanitaire des Aliments (AFSSA), Maisons-Alfort.

AFSSA, 2009. Avis de l'Agence Française de sécurité sanitaire des aliments relatif à la détermination de valeurs seuil en PCB-NDL comme outil d'appréciation du risque de contamination des poissons d'eau douce et de mer. AFSSA, Maisons-Alfort, p. 18.

Alomar, H., Lemarchand, C., Rosoux, R., Vey, D., Berny, P., 2016. Concentrations of organochlorine compounds (pesticides and $\mathrm{PCBs}$ ), trace elements ( $\mathrm{Pb}, \mathrm{Cd}, \mathrm{Cu}$, and $\mathrm{Hg}),{ }^{134} \mathrm{Cs}$, and ${ }^{137} \mathrm{Cs}$ in the livers of the European otter (Lutra lutra), great cormorant (Phalacrocorax carbo), and European catfish (Silurus glanis), collected from the Loire River (France). European Journal of Wildlife Research 62, 653-661 (10.1007/s10344-016-1038-5).

Aznar-Alemany, Ò., Trabalón, L., Jacobs, S., Barbosa, V.L., Tejedor, M.F., Granby, K., Kwadijk, C., Cunha, S.C., Ferrari, F., Vandermeersch, G., Sioen, I., Verbeke, W., Vilavert, L., Domingo, J.L., Eljarrat, E., Barceló, D., 2016. Occurrence of halogenated flame retardants in commercial seafood species available in European markets. Food Chem. Toxicol. 1-13. doi:10.1016/j.fct.2016.12.034.

Babut, M., Miege, C., Villeneuve, B., Abarnou, A., Duchemin, J., Marchand, P., Narbonne, J.F., 2009. Correlations between dioxin-like and indicators PCBs: potential consequences for environmental studies involving fish or sediment. Environ. Pollut. 157, 3451-3456.

Barón, E., Eljarrat, E., Barceló, D., 2012. Analytical method for the determination of halogenated norbornene flame retardants in environmental and biota matrices by gas chromatography coupled to tandem mass spectrometry. J. Chromatogr. A 1248, 154-160. doi:10.1016/j.chroma.2012.05.079.

Bodin, N., Tapie, N., Le Ménach, K., Chassot, E., Elie, P., Rochard, E., Budzinski, H, 2014. PCB 
contamination in fish community from the Gironde Estuary (France): Blast from the past. Chemosphere 98, 66-72. doi:10.1016/j.chemosphere.2013.10.003.

Brasseur, C., Pirard, C., Scholl, G., De Pauw, E., Viel, J.F., Shen, L., Reiner, E.J., Focant, J.F., 2014. Levels of dechloranes and polybrominated diphenyl ethers (PBDEs) in human serum from France. Environ. Int. 65, 33-40. doi:10.1016/j.envint.2013.12.014.

Commission Decision of 12 August 2002 (2002/657/EC) implementing Council Directive 96/23/EC concerning the performance of analytical methods and the interpretation of results.

402

Dang, V.D., Walters, D.M., Lee, C.M., 2010. Transformation of Chiral Polychlorinated Biphenyls (PCBs) in a Stream Food Web. Environ. Sci. Technol. 44, 2836-2841.

De La Torre, A., Alonso, M.B., Martínez, M.A., Sanz, P., Shen, L., Reiner, E.J., Lailson-Brito, J., Torres, J.P.M., Bertozzi, C., Marigo, J., Barbosa, L., Cremer, M., Secchi, E., Malm, O., Eljarrat, E., Barceló, D., 2012. Dechlorane-related compounds in franciscana dolphin (Pontoporia blainvillei) from southeastern and southern coast of Brazil. Environ. Sci. Technol. 46, 12364-12372. doi:10.1021/es302934p.

Eaufrance, http://www.pollutions.eaufrance.fr/pcb/, in French, accessed 21 $1^{\text {st }}$ January 2018.

EPA, 2014. An Alternatives Assessment for the Flame Retardant Decabromodiphenyl Ether (DecaBDE). United States Environmental Protection Agency, January 2014.

Eppe, G., Schaechtele, A., Haedrich, J., Fernandes, A., 2017. Guidance Document on Measurement Uncertainty for Laboratories performing PCDD/F and PCB Analysis using Isotope Dilution Mass Spectrometry. Working Group for Measurement Uncertainty in PCDD/F and PCB Analysis.

Feo, M.L., Barón, E., Eljarrat, E., Barceló, D., 2012. Dechlorane Plus and related compounds in aquatic and terrestrial biota: A review. Anal. Bioanal. Chem. 404, 2625-2637. doi:10.1007/s00216-0126161-x.

Giulivo, M., Capri, E., Kalogianni, E., Milacic, R., Majone, B., Ferrari, F., Eljarrat, E., Barceló, D., 2017. Occurrence of halogenated and organophosphate flame retardants in sediment and fish samples from three European river basins. Sci. Total Environ. 586, 782-791. 
doi:10.1016/J.SCITOTENV.2017.02.056.

Hoh, E., Zhu, Hites, R.A., 2006. Dechlorane Plus, a chlorinated flame retardant, in the Great Lakes. Environ. Sci. Technol. 40, 1184-1189. doi:10.1021/es051911h.

ISO 11352:2012. Water quality -- Estimation of measurement uncertainty based on validation and quality control data.

Jia, H., Sun, Y., Liu, X., Yang, M., Wang, D., Qi, H., Shen, L., Sverko, E., Reiner, E.J., Li, Y.-F., 2011. Concentration and bioaccumulation of Dechlorane compounds in coastal environment of Northern China. Environ. Sci. Technol. 45, 2613-2618.

Jondreville, C., Cariou, R., Travel, A., Belhomme, L.J., Dervilly-Pinel, G., Le Bizec, B., Huneau-Salaün, A., Le Bouquin-Leneveu, S., 2017. Hens can ingest extruded polystyrene in rearing buildings and lay eggs contaminated with hexabromocyclododecane. Chemosphere 186, 62-67. doi:10.1016/j.chemosphere.2017.07.117.

Kakimoto, K., Nagayoshi, H., Akutsu, K., Konishi, Y., Kajimura, K., Hayakawa, K., Toriba, A., 2015. Dechlorane Plus and decabromodiphenyl ether in atmospheric particles of northeast Asian cities. Environ. Sci. Pollut. Res. Int. 22, 14600-14605. doi:10.1007/s11356-014-2861-4.

Kakimoto, K., Nagayoshi, H., Yoshida, J., Akutsu, K., Konishi, Y., Toriba, A., Hayakawa, K., 2012. Detection of Dechlorane Plus and brominated flame retardants in marketed fish in Japan. Chemosphere 89, 416-419. doi:10.1016/j.chemosphere.2012.05.072.

Kang, J.H., Kim, J.C., Jin, G.Z., Park, H., Baek, S.Y., Chang, Y.S., 2010. Detection of Dechlorane Plus in fish from urban-industrial rivers. Chemosphere 79, 850-854. doi:10.1016/j.chemosphere.2010.02.051.

Kim, J., Son, M. hui, Kim, J., Suh, J., Kang, Y., Chang, Y.S., 2014. Assessment of Dechlorane compounds in foodstuffs obtained from retail markets and estimates of dietary intake in Korean population. J. Hazard. Mater. 275, 19-25. doi:10.1016/j.jhazmat.2014.04.032.

Kim, J., Son, M.H., Shin, E.S., Choi, S.D., Chang, Y.S., 2016. Occurrence of Dechlorane compounds and 
polybrominated diphenyl ethers (PBDEs) in the Korean general population. Environ. Pollut. 212, 330-336. doi:10.1016/j.envpol.2016.01.085.

L’Homme, B., Calaprice, C., Calvano, C.D., Zambonin, C., Leardi, R., Focant, J.F., 2015. Ultra-trace measurement of Dechloranes to investigate food as a route of human exposure. Chemosphere 139, 525-533. doi:10.1016/j.chemosphere.2015.07.043.

Luo, X.-J., Ruan, W., Zeng, Y.-H., Liu, H.-Y., Chen, S.-J., Wu, J.-P., Mai, B.-X., 2013. Trophic dynamics of hexabromocyclododecane diastereomers and enantiomers in fish in a laboratory feeding study. Environ. Toxicol. Chem. 32, 2565-2570 (10.1002/etc.2337).

Ma, J., Qiu, X., Liu, D., Zhao, Y., Yang, Q., Fang, D., 2014. Dechlorane Plus in surface soil of North China: Levels, isomer profiles, and spatial distribution. Environ. Sci. Pollut. Res. 21, 8870-8877. doi:10.1007/s11356-014-2823-x.

Rjabova, J., Bartkevics, V., Zacs, D., 2016. The occurrence of Dechlorane Plus and related norbornenebased flame retardants in Baltic wild salmon (Salmo salar). Chemosphere 147, 210-217. doi:10.1016/j.chemosphere.2015.12.122.

Sales, C., Poma, G., Malarvannan, G., Portolés, T., Beltrán, J., Covaci, A., 2017. Simultaneous determination of dechloranes, polybrominated diphenyl ethers and novel brominated flame retardants in food and serum. Anal. Bioanal. Chem. 4507-4515. doi:10.1007/s00216-017-0411-

Santín, G., Barón, E., Eljarrat, E., Barceló, D., 2013. Emerging and historical halogenated flame retardants in fish samples from Iberian rivers. J. Hazard. Mater. 263, 116-121. doi:10.1016/j.jhazmat.2013.08.068.

Shen, L., Reiner, E.J., MacPherson, K.A., Kolic, T.M., Helm, P.A., Richman, L.A., Marvin, C.H., Burniston, D.A., Hill, B., Brindle, I.D., McCrindle, R., Chittim, B.G., 2011a. Dechloranes 602, 603, 604 , dechlorane plus, and chlordene plus, a newly detected analogue, in tributary sediments of the Laurentian great lakes. Environ. Sci. Technol. 45, 693-699. doi:10.1021/es1027844.

Shen, L., Reiner, E.J., Helm, P.A., Marvin, C.H., Hill, B., Zhang, X., MacPherson, K.A., Kolic, T.M., Tomy, 
G.T., Brindle, I.D., 2011b. Historic trends of Dechloranes 602, 603, 604, Dechlorane plus and other norbornene derivatives and their bioaccumulation potential in Lake Ontario. Environ. Sci. Technol. 45, 3333-3340. doi:10.1021/es104328r.

Squadrone, S., Prearo, M., Nespoli, R., Scanzio, T., Abete, M.C., 2016. PCDD/Fs, DL-PCBs and NDLPCBs in European catfish from a northern Italian lake: the contribution of an alien species to human exposure. Ecotoxicol. Environ. Safe. 125, $170-175$ (http://dx.doi.org/10.1016/j.ecoenv.2015.12.004).

Stapleton, H.M., Misenheimer, J., Hoffman, K., Webster, T.F., 2014. Flame retardant associations between children's handwipes and house dust. Chemosphere 116, 54-60. doi:10.1016/j.chemosphere.2013.12.100.

Sun, R., Luo, X., Tang, B., Li, Z., Wang, T., Tao, L., Mai, B., 2016. Persistent halogenated compounds in fish from rivers in the Pearl River Delta, South China: Geographical pattern and implications for anthropogenic effects on the environment. Environ. Res. 146, 371-378. doi:10.1016/j.envres.2016.01.021.

Sverko, E., Tomy, G.T., Marvin, C.H., Zaruk, D., Reiner, E., Helm, P.E., Hill, B., McCarry, B., 2008. Dechlorane Plus Levels in Sediment of the Lower Great Lakes. Sci. Technol. 42, 361-366. doi:10.1021/es0710104.

Sverko, E., Tomy, G.T., Reiner, E.J., Li, Y.F., McCarry, B.E., Arnot, J.A., Law, R.J., Hites, R.A., 2011. Dechlorane plus and related compounds in the environment: A review. Environ. Sci. Technol. 45, 5088-5098. doi:10.1021/es2003028.

UNEP, 2001. Final Act of the Conference of Plenipotentiaries on the Stockholm Convention on Persistent Organic Pollutants. United Nations Environment Program: Geneva, Switzerland, p 44.

Von Eyken, A., Pijuan, L., Martí, R., Blanco, M.J., Díaz-Ferrero, J., 2016. Determination of Dechlorane Plus and related compounds (dechlorane 602, 603 and 604) in fish and vegetable oils. Chemosphere 144, 1256-1263. doi:10.1016/j.chemosphere.2015.10.001.

Wang, D.-G., Yang, M., Qi, H., Sverko, E., Ma, W.-L., Li, Y.-F., Alaee, M., Reiner, E.J., Shen, L., 2010. An 
Asia-Specific Source of Dechlorane Plus: Concentration, isomer profiles, and other related compounds. Environ. Sci. Technol. 44, 6608-6613. doi:10.1021/es101224y.

501

502

503

504

505

506

507

508

509

510

Wang, D.-G., Alaee, M., Sverko, E., Li, Y.-F., Reiner, E.J., Shen, L., 2011. Analysis and occurrence of emerging chlorinated and brominated flame retardants in surficial sediment of the Dalian costal area in China. J. Environ. Monit. 13, 3104. doi:10.1039/c1em10241a.

Wang, D.G., Guo, M.X., Pei, W., Byer, J.D., Wang, Z., 2015. Trophic magnification of chlorinated flame retardants and their dechlorinated analogs in a fresh water food web. Chemosphere 118, 293300. doi:10.1016/j.chemosphere.2014.09.057.

Wang, L., Jia, H., Liu, X., Yang, M., Hong, W., Sun, Y., Su, Y., Qi, H., Song, W., Lin, J., Li, Y.F., 2012. Dechloranes in a river in northeastern China: Spatial trends in multi-matrices and bioaccumulation in fish (Enchelyopus elongatus). Ecotoxicol. Environ. Saf. 84, 262-267. doi:10.1016/j.ecoenv.2012.07.018.

Wang, P., Zhang, Q., Zhang, H., Wang, T., Sun, H., Zheng, S., Li, Y., Liang, Y., Jiang, G., 2016. Sources and environmental behaviors of Dechlorane Plus and related compounds - A review. Environ. Int. 88, 206-220. doi:10.1016/j.envint.2015.12.026.

Wong, C.S., Lau, F., Clark, M., Mabury, S.A., Muir, D.C.G., 2002. Rainbow trout (Oncorhynchus mykiss) can eliminate chiral organochlorine compounds enantioselectively. Environ. Sci. Technol. 36, 1257-1262.

Xian, Q., Siddique, S., Li, T., Feng, Y. lai, Takser, L., Zhu, J., 2011. Sources and environmental behavior of dechlorane plus - A review. Environ. Int. 37, 1273-1284. doi:10.1016/j.envint.2011.04.016.

Yang, R., Zhang, S., Li, X., Luo, D., Jing, C., 2016. Dechloranes in lichens from the southeast Tibetan Plateau: Evidence of long-range atmospheric transport. Chemosphere 144, 446-451. doi:10.1016/j.chemosphere.2015.09.011.

Yu, D., Yang, J., Li, T., Feng, J., Xian, Q., Zhu, J., 2015. Levels and distribution of Dechloranes in sediments of Lake Taihu, China. Environ. Sci. Pollut. Res. 22, 6601-6609. doi:10.1007/s11356014-3794-7. 
525 Zhang, Y., Wu, J.P., Luo, X.J., Wang, J., Chen, S.J., Mai, B.X., 2011. Tissue distribution of Dechlorane Plus and its dechlorinated analogs in contaminated fish: High affinity to the brain for anti-DP. Environ. Pollut. 159, 3647-3652. doi:10.1016/j.envpol.2011.07.026. 


\section{$531 \quad$ Figure captions}

532 Figure 1. Locations of the 22 sampling areas in France (map background from 533 http://cartographie.nature33.fr).

534 Figure 2. Overview of the sample preparation procedure for the analysis of DRCs in fish muscle.

535 Figure 3. Concentrations (pg.g $\left.{ }^{-1} \mathrm{ww}\right)$ of syn-DP versus anti-DP when both values were $\geq \operatorname{LOR}(n=33)$. 
537 Table 1. Concentration (pg. $g^{-1}$ ww and Iw) of DRCs obtained for Silurus spp. samples $(n=102)$ from French rivers. LB: lower-bound; UB: upper-bound.

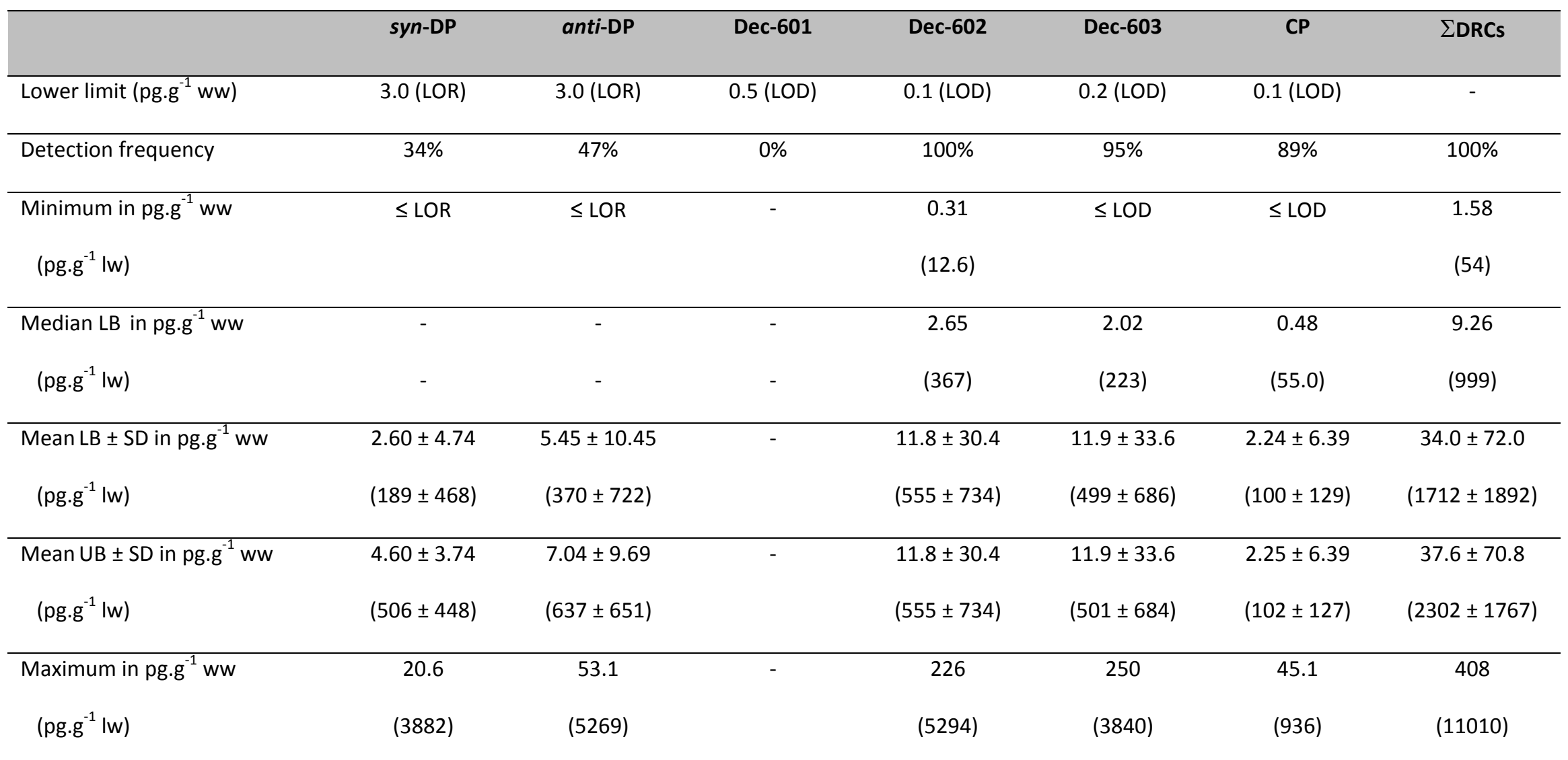


539 Table 2. Correlation coefficients (Spearman, $\rho$ ) between DRC concentrations (ww / Iw based values).

540 ns: $P$-value $>0.05 ;{ }^{*} P>0.01 ; * * \leq 0.01 ; * * P \leq 0.0001$

\begin{tabular}{lcccc}
\hline Variable & Dec-603 & anti-DP & syn-DP & CP \\
\hline Dec-602 & $0.67^{* * *} / 0.48^{* * *}$ & $0.44^{* *} / 0.22^{\text {ns }}$ & $0.38^{*} / 0.09^{\text {ns }}$ & $0.65^{* * *} / 0.41^{* * *}$ \\
CP & $0.78^{* * *} / 0.71^{* * *}$ & $0.58^{* *} / 0.22^{\text {ns }}$ & $0.32^{\text {ns }} / 0.25^{\text {ns }}$ & \\
syn-DP & $0.34^{\text {ns }} / 0.12^{\text {ns }}$ & $0.75^{* * *} / 0.86^{* * *}$ & & \\
anti-DP & $0.55^{* *} / 0.23^{\text {ns }}$ & & & \\
& & & \\
\hline
\end{tabular}

541

542 


\section{Figure 1}

Click here to download Figure: Figure 1 (Map).pptx Marne

Author-produced version of the article published in Chemosphere, 2018, 207, 413-4 PM MUS

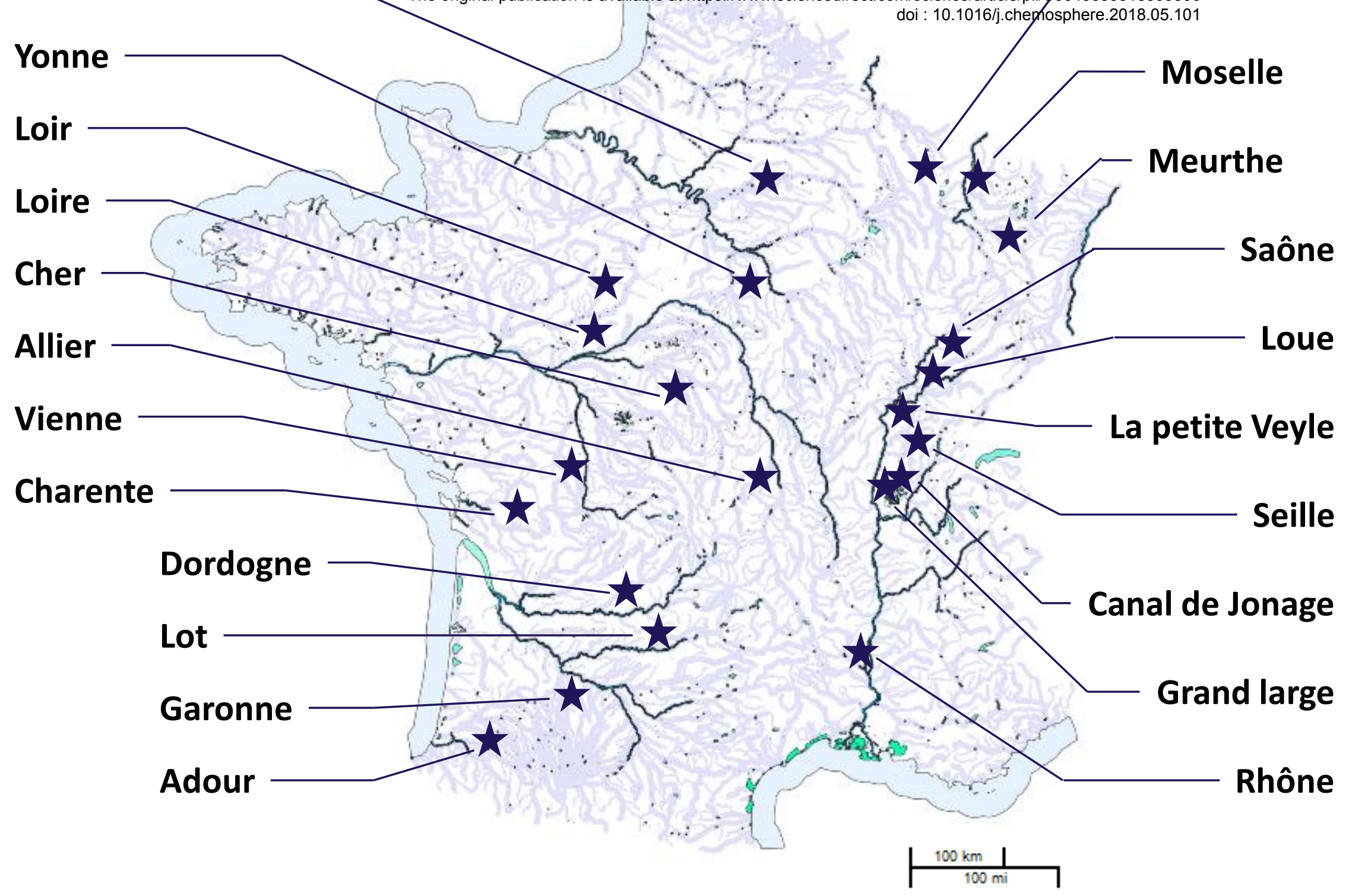




\section{Figure 2}

\section{Lyophilisation}

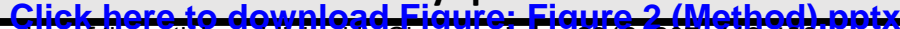

ersion of the article published in Chernosphe re,2018, 207, 413-420."

ps://www.sciencedirect.com/science/article/ $\mathrm{r} / \mathrm{S} 0045653518309500$

\section{Pressurised Liquid Extraction}

Toluene/acetone 7:3 (v/v)

$4 \mathrm{ng}$ of internal standards

\section{Multilayer silica gel column}

Sodium sulphate, neutral ( $5 \mathrm{~g}$ ), basic ( $5 \mathrm{~g})$, neutral ( $5 \mathrm{~g}$ ),

$\mathrm{H}_{2} \mathrm{SO}_{4} 22 \%$ (20 g), $\mathrm{H}_{2} \mathrm{SO}_{4} 44 \%$ (25 g), sodium sulphate

$$
n \text {-hexane }(120 \mathrm{~mL})
$$

\section{Gel Permeation Chromatography}

Bio-Beads SX-3

Ethyl acetate/cyclohexane 1:1 $(\mathrm{v} / \mathrm{v})$ at $5 \mathrm{~mL} \cdot \mathrm{min}^{-1}$

24-36 $\mathrm{min}$

$0.8 \mathrm{ng}$ of recovery standard

$$
\text { GC-EI-HRMS }(R=10,000)
$$




\section{Figure 3}

Click here to download Figure: Ehgure 3 (f_anti).ppptx

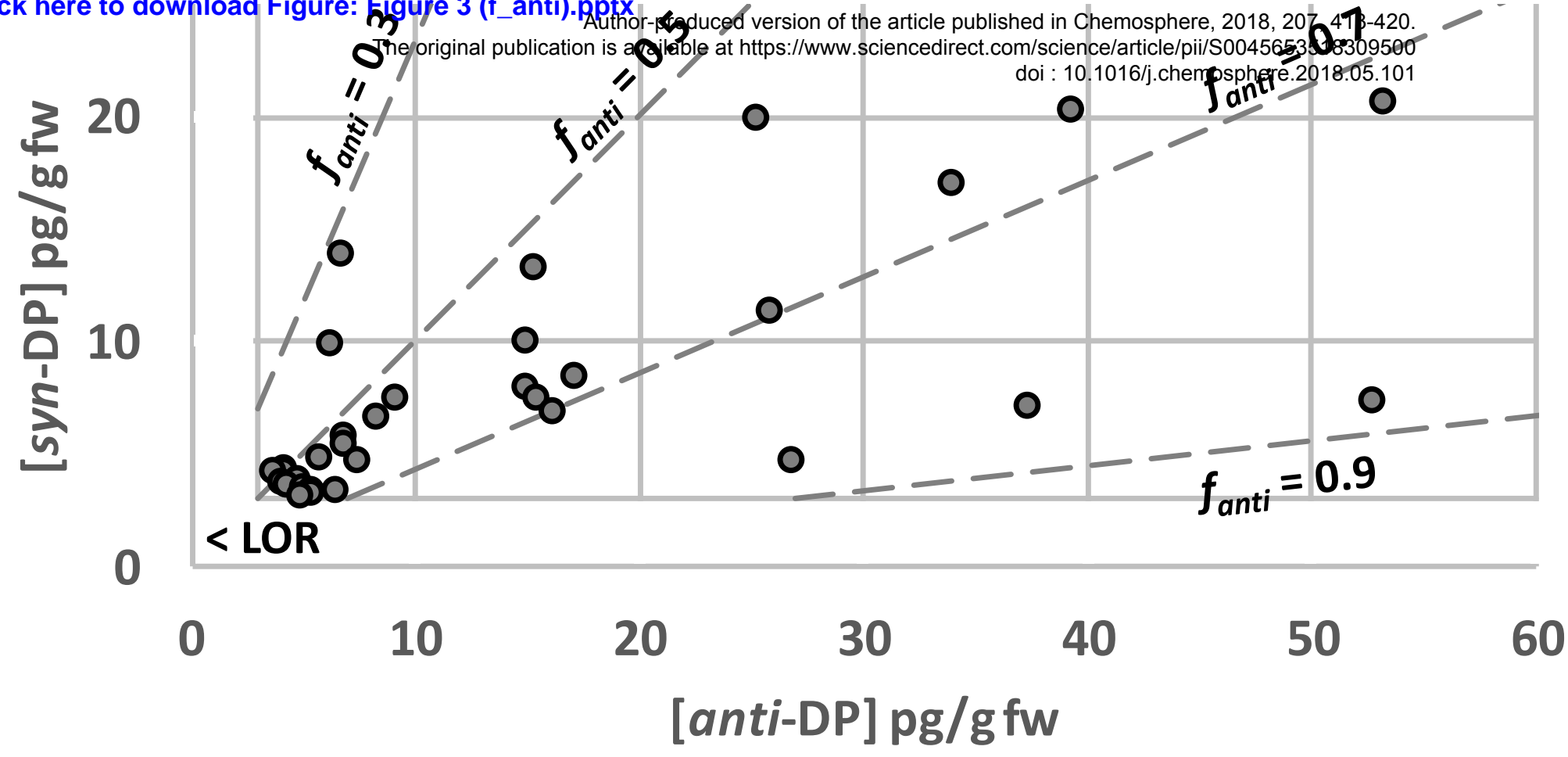

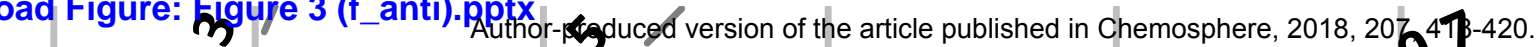

0

0

20

[anti-DP] pg/g fw

doi : 10.1016/j.chemsphere.2018.05.101

$f_{\text {anti }}=0.9$ 